\title{
Pseudowintera colorata (Raoul) Dandy Hydro-Alcohol Leaf Extract Inhibits Bacterial Triggers of Some Autoimmune Inflammatory Diseases
}

\author{
Celia Barillot ${ }^{1,2}$ Craig Davis $^{3,4}$, Ian Edwin Cock ${ }^{1,5 *}$ \\ 'Environmental Futures Research Institute, Griffith University, Brisbane, AUSTRALIA. \\ ${ }^{2}$ School of Biology, Ecole de Biologie Industrielle (EBI), Cergy, FRANCE. \\ ${ }^{3}$ Botanical Medicine Research Institute, Brisbane, AUSTRALIA. \\ ${ }^{4}$ Bioextracts P/L, Brisbane, AUSTRALIA. \\ ${ }^{5}$ School of Natural Sciences, Griffith University, Brisbane, AUSTRALIA.
}

\begin{abstract}
Introduction: Pseudowintera colorata (Raoul) Dandy is an evergreen shrub which is endemic to New Zealand. Decoctions, infusions and essential oils produced from the leaves were used traditionally to treat a variety of bacterial diseases. Despite this, P. colorata leaf extracts have not been rigorously examined for inhibitory activity against bacterial triggers of autoimmune inflammatory diseases. Methods: A P. colorata hydro-alcohol leaf extract was analysed for antioxidant capacity by the DPPH free radical scavenging assay. Growth inhibitory activities against bacterial species associated with initiating rheumatoid arthritis, ankylosing spondylitis, multiple sclerosis and rheumatic fever were determined by disc diffusion assay and quantified by MIC determination. Toxicity was determined by Artemia franciscana bioassay. Results: The P. colorata hydro-alcohol leaf extract displayed good DPPH radical scavenging activity, with an antioxidant capacity of $52 \mu \mathrm{g} /$ $\mathrm{mL}$ ascorbic acid equivalency. The extract inhibited the growth of all of the bacterial triggers of autoimmune inflammatory diseases tested. It was a particularly potent inhibitor of $A$. baylyi, with MIC values as low as $427 \mu \mathrm{g} /$ $\mathrm{mL}$ against the clinical strain. P. mirabilis and $P$. vulgaris were also highly susceptible to the $P$. colorata hydro-alcohol leaf extract, with MIC values of approximately $800-900 \mu \mathrm{g} / \mathrm{mL}$ against all strains. The extract was also a moderate growth inhibitor (MIC $>1000 \mu \mathrm{g} / \mathrm{mL}$ ) of all other bacterial strains
\end{abstract}

tested. The extract was determined to be nontoxic in the Artemia franciscana nauplii bioassay with $24 \mathrm{~h} \mathrm{LC50}$ values substantially $>1000 \mu \mathrm{g} / \mathrm{mL}$, indicating its safety for therapeutic use. Conclusion: The lack of toxicity of the $P$. colorata leaf extracts and their growth inhibitory bioactivity against a panel of bacterial triggers of autoimmune inflammatory diseases indicate their potential in the prevention and treatment of these diseases in genetically susceptible individuals.

Key words: Winteraceae, Horopito, Pepperwood, Autoimmune Inflammatory Disease, Rheumatoid Arthritis, Ankylosing Spondylitis.

\section{Correspondence:}

lan Edwin Cock

Environmental Futures Research Institute, Griffith University, Brisbane, Australia and School of Natural Sciences, Griffith University, Brisbane, AUSTRALIA.

Phone no: +61 737357637 ; Fax: +61 737355282

E-mail: I.Cock@griffith.edu.au (I. E. Cock).

DOI : $10.5530 /$ pc.2017.4.24

\section{INTRODUCTION}

Winteraceae is a family of flowering plants consisting of approximately 90 species of trees and shrubs divided into 5 genera (Drimys, Pseudowintera, Takhtajania, Tasmannia and Zygogynum). ${ }^{1}$ The Winteraceae have developed as almost exclusively southern hemisphere plants, originating from precursor species on the Gondwanna super continent. Their current distribution ranges from the cool climate regions of the southern Australia and New Zealand through to the temperate and tropical regions of Borneo, Madagascar, Molucca, New Caledonia, Papua new Guinea, the Philippines and Southern and Central America, with the majority concentrated in Australasia and Malanesia. ${ }^{2}$ The Winteraceae are characterized as woody evergreen plants with vesselless xylem and plicate carpels. ${ }^{1,2}$ They generally have leaves without stipules. The leaves, which are almost always glabrous, have entire margins and are spirally arranged. Flowers are terminal, are generally condensed and can be either bisexual or unisexual. The fruit forms as a fleshy berry with a hard seed. Many Winteraceae species are fragrant and are often used to produce essential oils. Zygogynum is the largest Winteraceae genus with approximately 50 species. ${ }^{1-3}$ Until recently, Belliolum, Bubbia and Exospermum were classified as distinct genera. Although most botanists now classify these as subgroupings of the Zygogynum genus. Tasmannia is the next largest genus with approximately 30 species. ${ }^{4}$ Drimys consists of 6 species, Pseudowintera of 3 species, and Takhtajania consists of a single species. ${ }^{4}$

Members of family Winteraceae have been used for a broad range of di- etary and medicinal purposes by a wide variety of ethnic and cultural groupings. The best documented of these is the South American species Drimys winteri. The stem and bark of this species has been used as a stimulant and as a tonic in traditional Brazilian medicinal systems. ${ }^{5}$ They are also used for a wide variety of medicinal purposes including as an analgesic, as well as to treat diarrhoea, inflammation, and ulcers. ${ }^{5}$ This species also has widespread usage in the treatment of scurvey due to its high antioxidant content. ${ }^{6}$ Of the other Winteraceae species, several have a history of ethnobotanical usage, usually for purposes related to their high antioxidant contents and as a flavourant.

Pseudowintera colorata (Raoul) Dandy (horopito) is one of only 3 species within the genus Pseudowintea (the others are P. axillaris (J.R. Forst. \& G. Forst.) Dandy and $P$ traversii (Buchanan) Dandy). All Pseudowintera spp. are endemic to New Zealand. $P$. colorata is commonly known as mountain horopito or New Zealand pepperwood due to the hot, peppery flavour of its leaves which are yellow/green with red blotches (Figure 1a). It grows as a shrub or small tree (to $2.5 \mathrm{~m}$ high) with a multi-branched stem. The leaves are alternate with long pinnate lobes. The flowers appear in the warmer summer months and develop into fleshy red lobed berries (Figure 1b) during autumn. As with many of the other Winteraceae species, $P$. colorata leaves and berries have historical uses as food and as a medicinal plant. The leaves are particularly useful as a flavorant. Traditionally, the leaves are dried and ground into a powder which is used as a substitute for black pepper. All parts of the plant are reputed to have a 
high antioxidant capacity and are rich in ascorbic acid. ${ }^{6}$

The New Zealand Maori people have used P. colorata medicinally to treat a variety of diseases including sexually transmitted infections, ringworm, chaffed skin and other skin diseases. ${ }^{7}$ It is particularly effective against Candida albicans infections and is reputed to aid wound healing and to have antibacterial, anti-inflammatory anti-allergic and insecticide effects. Early European settlers in New Zealand also used P. colorata medicinally. The leaves were chewed or prepared as an infusion as a painkiller, as well as for the treatment of diarrhoea. ${ }^{7}$ Furthermore, due to its high antioxidant capacity, $P$. colorata has potential for the treatment of multiple other chronic diseases. Oxidative stress is associated with many human diseases including cancer, chronic inflammation, atherosclerosis and Alzheimer's disease. ${ }^{8}$ Individuals with elevated dietary intakes of non-enzymatic antioxidants such as vitamins $\mathrm{A}, \mathrm{C}$ and $\mathrm{E}$ are less likely to suffer from some diseases including cancer and chronic inflammation. ${ }^{9}$ Furthermore, several studies have demonstrated bacterial growth inhibitory and anti-inflammatory activities for several culinary plants with high antioxidant capacities, and have linked the bioactivities to their free radical scavenging activities. ${ }^{10-14}$ As with many other Winteraceae, $P$. colorata leaves are particularly rich in the sesquiterpenoid polygodial (Figure 1c), which is largely responsible for its characteristic hot peppery flavour. This compound is also believed to be responsible for many of the medicinal properties of this species, as well as other members of the family Winteraceae. ${ }^{6}$ The leaves are also a good source of other terpenoids including piperitone (Figure 1d).

Autoimmune inflammatory disorders (e.g. rheumatoid arthritis, ankylosing spondylitis, multiple sclerosis and rheumatic fever) are a group of debilitating conditions which afflict genetically susceptible individuals. There are no cures for any of these conditions and current treatment strategies instead aim to alleviate the symptoms (particularly pain, swelling and inflammation) with analgesics and anti-inflammatory agents and/or to modify the disease process through the use of disease modifying drugs. None of these treatments is ideal as prolonged usage of these drugs is often accompanied by unwanted side effects and toxicity. ${ }^{15}$ There is a need to develop safe, more effective treatments which will not only alleviate the symptoms, but may also cure or prevent the disease. A greater understanding of the onset and progression of these disorders should greatly assist in more relevant drug discovery and development.

Autoimmune inflammatory disorders are triggered in susceptible individuals by specific microbial infections. Serotyping studies have identified several of the bacterial triggers of some of these conditions and the bacterial antigens responsible for the induction of an immune response (Table 1). A major microbial trigger of rheumatoid arthritis has been identified as $P$. mirabilis ${ }^{16}$ a normal part of the human gastrointestinal flora. Similarly, K. pneumoniae has been shown to initiate ankylosing spondylitis ${ }^{17}$ and $A$. baylyi and $P$. aeruginosa have been linked with the onset of multiple sclerosis. ${ }^{18}$ Borelia burgforferi is linked with Lyme disease. ${ }^{19}$ Whilst microbial triggers have also been postulated for lupus, the specific causative agents are yet to be identified. Similarly, members of the Enterobacteriaceae family are associated with Graves' disease and Kawasaki syndrome and Mycoplasma pneumoniae is associated with several demyelinating diseases. ${ }^{20}$ The development of antibiotic agents targeted at the specific bacterial triggers of autoimmune inflammatory disorders would enable afflicted individuals to target these microbes and thus prevent the onset of the disease and reduce the severity of the symptoms once the disease has progressed.

A re-examination of traditional medicines for the treatment of inflammation and rheumatic conditions is an attractive prospect as the antiseptic qualities of medicinal plants have been long recognised and recorded. Furthermore, there has recently been a revival of interest in herbal medications due to a perception that there is a lower incidence of adverse reactions to plant preparations compared to synthetic pharmaceuticals. Antimicrobial plant extracts with high antioxidant contents are particularly attractive as they may treat the symptoms of inflammation as well as blocking the microbial trigger and thus may have pluripotent effects. The current study was undertaken to examine the growth inhibitory activity of a $P$. colorata hydro-alcohol extract against bacterial species associated with the onset of four autoimmune diseases.

\section{MATERIALS AND METHODS}

\section{Pseudowintera colorata extract}

Pseudowintera colorata (Raoul) Dandy hydro-alcohol leaf extract was obtained from Optimal RX, Australia as a $45 \%$ ethanol extract. A $10 \mathrm{~mL}$ volume of the extract was dried by rotary evaporation in an Eppendorf concentrator 5301 and subsequently dissolved in $10 \mathrm{~mL}$ sterile deionised water (containing $1 \%$ DMSO). The extract was passed through $0.22 \mu \mathrm{m}$ filter (Sarstedt) and stored at $4{ }^{\circ} \mathrm{C}$ until use.

\section{Qualitative phytochemical studies}

Phytochemical analysis of the $P$. colorata hydro-alcohol leaf extract for the presence of saponins, phenolic compounds, flavonoids, phytosteroids, triterpenoids, cardiac glycosides, anthraquinones, tannins and alkaloids was conducted by previously described assays. ${ }^{23,24,25}$

\section{Antioxidant capacity determination}

The antioxidant capacity of each sample was assessed using the DPPH free radical scavenging method. ${ }^{26}$ with modifications. Briefly, DPPH solution was prepared fresh each day as a $400 \mu \mathrm{M}$ solution by dissolving DPPH (Sigma) in AR grade methanol (Ajax, Australia). The initial absorbance of the DPPH solution was measured at $515 \mathrm{~nm}$ using a Molecular Devices, Spectra Max M3 plate reader and did not change significantly throughout the assay period. A $2 \mathrm{~mL}$ aliquot of each extract was evaporated and the residue was resuspended in $2 \mathrm{~mL}$ of methanol. Each extract was added to a 96-well plate in amounts of $5,10,25,50,75 \mu \mathrm{L}$ in triplicate. Methanol was added to each well to give a volume of 225 $\mu \mathrm{L}$. A volume of $75 \mu \mathrm{L}$ of the fresh DPPH solution was added to each

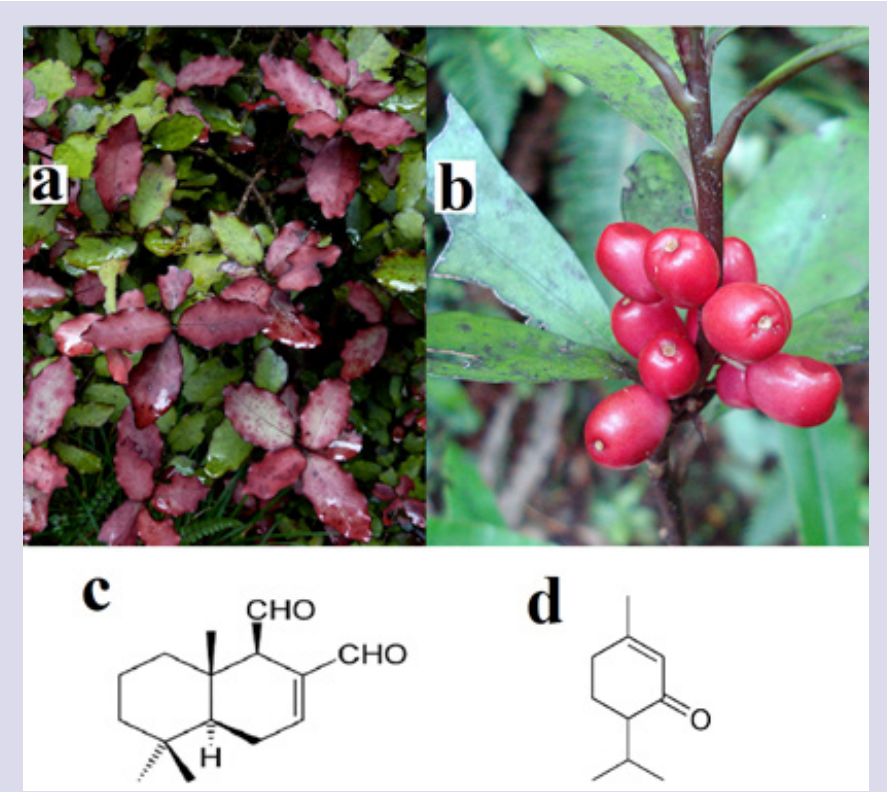

Figure 1: P. colorata (a) leaves and (b) fruit, as well as the chemical structures of (c) polygodial and, (d) piperitone. 
Table 1: The bacterial triggers of some autoimmune inflammatory diseases examined in this study as well as the bacterial antigen and host susceptibility antigen sequences.

\begin{tabular}{|c|c|c|c|c|c|c|}
\hline Disease & Bacterial Trigger & Bacterial Antigen & $\begin{array}{l}\text { Bacterial } \\
\text { Sequence }\end{array}$ & Host Antigen & Host Sequence & References \\
\hline \multirow[t]{2}{*}{$\begin{array}{l}\text { Rheumatoid } \\
\text { arthritis }\end{array}$} & $\begin{array}{l}\text { Proteus mirabilis and } \\
\text { possibly also other } \\
\text { Proteus spp. }\end{array}$ & haemolysin & ESRRAL & $\begin{array}{l}\text { MHC class } 2 \text { allele } \\
\text { HLA-DR4 }\end{array}$ & EQ/KRRAA & $16-22$ \\
\hline & & urease & IRRET & type XI collagen & LRREI & $15-21$ \\
\hline \multirow[t]{3}{*}{$\begin{array}{l}\text { Ankylosing } \\
\text { spondylitis }\end{array}$} & Klebsiella pneumoniae & $\begin{array}{l}\text { nitrogenase reductase } \\
\text { enzyme }\end{array}$ & QTDRED & $\begin{array}{c}\text { MHC class } 1 \text { allele } \\
\text { HLA-B27 }\end{array}$ & QTDRED & 16 \\
\hline & & pullulanase & DRDE & $\begin{array}{c}\text { MHC class } 1 \text { allele } \\
\text { HLA-B27 }\end{array}$ & DRED & 16 \\
\hline & & pullulanase & GxP & $\begin{array}{l}\text { types I, III and IV } \\
\text { collagen }\end{array}$ & GxP & 16 \\
\hline \multirow[t]{4}{*}{$\begin{array}{l}\text { Multiple } \\
\text { sclerosis }\end{array}$} & Pseudomonas aeriginosa & Ү-CMLD & TRHAYG & $\begin{array}{l}\text { Myelin-neuronal } \\
\text { antigen MBP }\end{array}$ & SRFSYG & 17 \\
\hline & Acinetobacter spp. & 4-CMLD & SRFAYG & $\begin{array}{l}\text { Myelin-neuronal } \\
\text { antigen MBP }\end{array}$ & SRFSYG & 17 \\
\hline & & 3-OACT-A & LTRAGK & $\begin{array}{l}\text { Myelin-neuronal } \\
\text { antigen MOG }\end{array}$ & LYRDGK & 17 \\
\hline & & $\begin{array}{c}\text { Acinteobacter regulatory } \\
\text { protein }\end{array}$ & ${ }^{\star}$ KKVEEI & $\begin{array}{l}\text { Neurofilament-M } \\
\text { protein }\end{array}$ & ${ }^{\star}$ KKVEEI & $17-19$ \\
\hline
\end{tabular}

MOG = myelin oligodendrocyte glycoprotein; $\mathrm{MBP}=$ myelin basic protein; 4-CMLD = 4-carboxy-muconolactone decarboxylase; 3-OACT-A = 3-oxoadipate CoAtransferase; $\Upsilon$-CMLD $=\Upsilon$-carboxy-muconolactone decarboxylase. ${ }^{*}$ indicates the sequence likely to be responsible for crossreactivity although this is yet to be confirmed.

well to give a total reaction volume of $300 \mu \mathrm{L}$. A blank of each extract concentration, methanol solvent, and DPPH was also performed in triplicate. Ascorbic acid was prepared fresh and examined across the range 0-25 $\mu$ g per well as a reference and the absorbance were recorded at 515 $\mathrm{nm}$. All tests were performed in triplicate and triplicate controls were included on each plate. The antioxidant capacity based on DPPH free radical scavenging ability was determined for each extract and expressed as $\mu \mathrm{g}$ ascorbic acid equivalents per $\mathrm{mL}$ of extract.

\section{Antibacterial screening}

\section{Test microorganisms}

All media was supplied by Oxoid Ltd. Reference strains of Proteus mirabilis (ATCC21721), Proteus vulgaris (ATCC21719), Klebsiella pneumoniae (ATCC31488), Acinitobacter baylyi (ATCC33304) and Pseudomonas aeruginosa (ATCC39324) were purchased from American Tissue Culture Collection, USA. All other clinical microbial strains were obtained from the School of Natural Sciences teaching laboratory, Griffith University. All stock cultures were subcultured and maintained in nutrient broth at $4^{\circ} \mathrm{C}$.

\section{Evaluation of antimicrobial activity}

Antimicrobial activity of all plant extracts was determined using a modified disc diffusion assay. ${ }^{27-29}$ Briefly, $100 \mu \mathrm{L}$ of each bacterial culture was grown in $10 \mathrm{~mL}$ of fresh nutrient broth until they reached a count of $\sim 10^{8}$ cells $/ \mathrm{mL}$. A volume of $100 \mu \mathrm{L}$ of the bacterial suspension was spread onto nutrient agar plates and extracts were tested for antibacterial activity using $5 \mathrm{~mm}$ sterilised filter paper discs. Discs were infused with $10 \mu \mathrm{L}$ of the plant extracts, allowed to dry and placed onto the inoculated plates. The plates were allowed to stand at $4{ }^{\circ} \mathrm{C}$ for $2 \mathrm{~h}$ before incubation at 30 ${ }^{\circ} \mathrm{C}$ for $24 \mathrm{~h}$. The diameters of the inhibition zones were measured to the closest whole millimetre. Each assay was performed in at least triplicate. Mean values $( \pm$ SEM) are reported in this study. Standard discs of ampicillin $(10 \mu \mathrm{g})$ were obtained from Oxoid, Australia and were used as positive controls to compare antibacterial activity. Filter discs infused with $10 \mu \mathrm{L}$ of distilled water were used as a negative control.

\section{Minimum inhibitory concentration (MIC) determination}

The minimum inhibitory concentration (MIC) of each extract against susceptible bacteria was determined as previously described. ${ }^{30,31}$ Briefly, the $P$. colorata hydro-alcohol leaf extract was diluted in deionised water and tested across a range of concentrations. Discs were infused with 10 $\mu \mathrm{L}$ of the test dilutions, allowed to dry and placed onto inoculated plates. The assay was completed as outlined above and graphs of the zone of inhibition versus concentration were plotted for each extract. Linear regression was used to determine the MIC values of each extract.

\section{Toxicity screening}

\section{Reference toxin for toxicity screening}

Potassium dichromate $\left(\mathrm{K}_{2} \mathrm{Cr}_{2} \mathrm{O}_{7}\right)$ (AR grade, Chem-Supply, Australia) was prepared as a $4 \mathrm{mg} / \mathrm{mL}$ solution in distilled water and was serially diluted in artificial seawater for use in the Artemia franciscana nauplii bioassay. 


\section{Artemia franciscana nauplii toxicity screening}

Toxicity was tested using an adapted Artemia franciscana nauplii lethality assay. ${ }^{32-34}$ Briefly, $400 \mu \mathrm{L}$ of seawater containing approximately 49 (mean 48.8, $\mathrm{n}=75, \mathrm{SD} 10.7$ ) A. franciscana nauplii were added to wells of a 48 well plate and immediately used for bioassay. A volume of $400 \mu \mathrm{L}$ of diluted plant extracts or the reference toxin were transferred to the wells and incubated at $25 \pm 1^{\circ} \mathrm{C}$ under artificial light (1000 Lux). A $400 \mu \mathrm{L}$ seawater negative control was run in triplicate for each plate. All treatments were performed in at least triplicate. The wells were checked at regular intervals and the number of dead counted. The nauplii were considered dead if no movement of the appendages was detected within 10 seconds. After $24 \mathrm{~h}$, all nauplii were sacrificed and counted to determine the total $\%$ mortality per well. The $\mathrm{LC}_{50}$ with $95 \%$ confidence limits for each treatment was determined using probit analysis.

\section{Statistical analysis}

Data are expressed as the mean \pm SEM of at least three independent experiments.

\section{RESULTS}

\section{Qualitative phytochemical screening and antioxidant capacity determination}

A $10 \mathrm{~mL}$ volume of the $45 \%$ P. colorata hydro-alcohol leaf extract was dried by rotary evaporation in an Eppendorf concentrator 5301. The resultant dry extract was subsequently redissolved in $10 \mathrm{~mL}$ deionised water (containing 1\% DMSO). Qualitative phytochemical studies of the $P$. colorata leaf extract showed high levels of phenolics, saponins and flavonoids, and low levels of triterpenoids and tannins (Table 2). An antioxidant capacity (expressed as ascorbic acid equivalence) of $52 \mu \mathrm{g}$ ascorbic acid equivalence per $\mathrm{mL}$ of $P$. colorata hydro-alcohol leaf extract was also calculated.

\section{Antimicrobial activity}

To determine the growth inhibitory activity of the $P$. colorata hydro-alcohol leaf extract against the panel of pathogenic bacteria, $10 \mu \mathrm{L}$ of the extract was screened in the disc diffusion assay. Both reference and clinical strains of Proteus mirabilis were inhibited by the P. colorata hydroalcohol leaf extract (Figure 2). However, inhibition was weak (as judged by the zones of inhibition), with inhibition zones of $7.9 \pm .3 \mathrm{~mm}$ and 8.2

Table 2: Qualitative phytochemical screenings and antioxidant capacities of the $P$. colorata hydro-alcohol leaf extract.

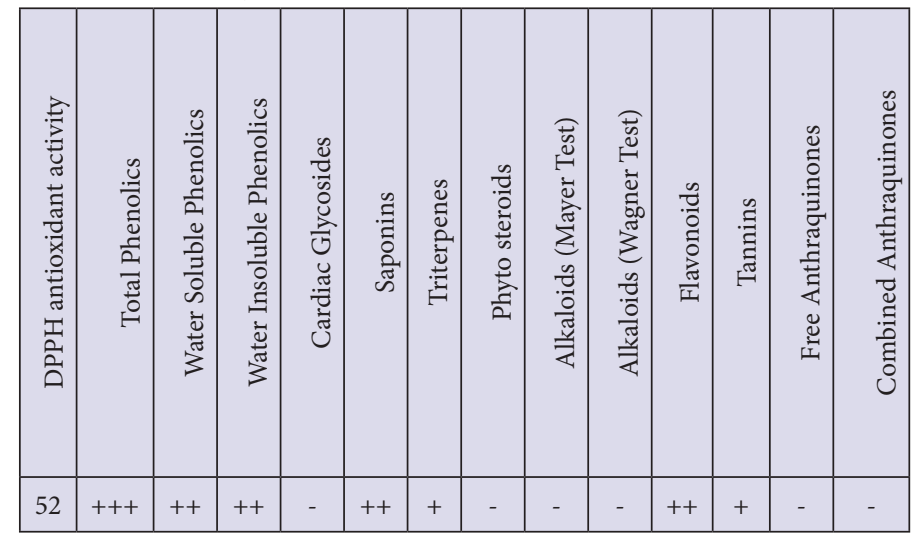

+++ indicates a large response; ++ indicates a moderate response; + indicates a minor response; - indicates no response in the assay. Antioxidant capacity was determined by DPPH reduction and is expressed as $\mu \mathrm{g}$ ascorbic acid equivalence per $\mathrm{mL}$ hydro-alcohol extract. $\pm 0.4 \mathrm{~mm}$ measured for the reference and clinical strains respectively. It is noteworthy that these $P$. mirabilis strains were also relatively resistant to the ampicillin control (inhibition zone of $8.3 \pm 0.3 \mathrm{~mm}$ ). This is consistent with the susceptibility profiles of these bacterial strains previously reported in other studies. ${ }^{10-12}$ In contrast, both $P$. mirabilis strains were highly susceptible to chloramphenicol $(10 \mu \mathrm{g}$ : inhibition zones of $11.3 \pm 0.6 \mathrm{~mm}$ and $12.0 \pm 0.5 \mathrm{~mm}$ for the reference and clinical strains respectively). Similarly, P. vulgaris growth was also susceptible to inhibition by the $P$. colorata leaf hydro-alcohol extract (Figure 3 ). Indeed, an $8.3 \pm 0.3 \mathrm{~mm}$ zone of inhibition was measured for $P$. vulgaris growth. This indicates that $P$. vulgaris is more susceptible to the extract than $P$. mirabilis was. This inhibition also compares well with the ampicillin control (inhibition zone of $7.9 \pm 0.3 \mathrm{~mm}$ ) but is substantially less potent than the chloramphenicol control $(13.7 \pm 0.6 \mathrm{~mm})$.

The growth of both reference and clinical K. pneumoniae strains was inhibited by the $P$. colorata leaf hydro-alcohol extract (Figure 4), albeit with smaller zones of inhibition compared to the growth inhibition of the Proteus spp. Interestingly, both $K$. pneumoniae strains were completely resistant to ampicillin and had only relatively small zones of inhibition when tested against chloramphenicol, indicating that both K. pneumoniae strains were antibiotic resistant strains.

In contrast, potent $A$. baylyi growth inhibition was noted for the P. colorata leaf hydro-alcohol extract (Figure 5 zones of inhibition of $9.6 \pm 0.3$ $\mathrm{mm}$ and $9.0 \pm 0.5 \mathrm{~mm}$ against the reference and clinical strains respectively). This is a particularly significant result as the ampicillin control only inhibited $A$. baylyi growth with low efficacy, indicating that the $A$. baylyi strain tested in our study was ampicillin resistant. Indeed, previous studies from our group have also shown the low susceptibility of these A. baylyi strains to a number of conventional antibiotics. ${ }^{10,11}$ In contrast, both A. baylyi strains were highly susceptibile to chloramphenicol (12.6 $\pm 0.3 \mathrm{~mm}$ and $11.8 \pm 0.4 \mathrm{~mm}$ against the reference and clinical strains respectively). In contrast, only relatively weak $P$. aeruginosa growth inhibition was noted for the P. colorata leaf hydro-alcohol extracts (Figure 6 zone of inhibition $<7 \mathrm{~mm}$ for both strains). However, this compares well to the ampicillin $(6.4 \pm 0.3 \mathrm{~mm}$ for the reference strain $)$ and chloramphenicol controls $(7.8 \pm 0.4 \mathrm{~mm}$ and $7.6 \pm 0.3 \mathrm{~mm}$ for the reference and clinical strains respectively).

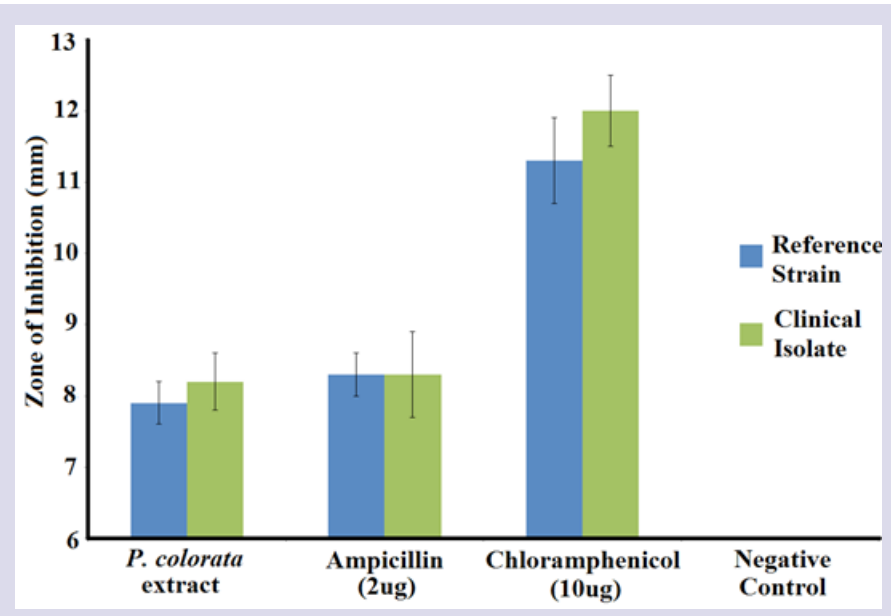

Figure 2: Growth inhibitory activity of $P$. colorata leaf hydro-alcohol extract and the ampicillin $(2 \mu \mathrm{g})$ and chloramphenicol $(10 \mu \mathrm{g})$ controls against $P$. mirabilis measured as zones of inhibition $(\mathrm{mm})$. The blue bars represent the inhibitory activity against the reference strain (ATCC:21721) and the green bars represent the zones of inhibition against the clinical strain. All determinations were in at least triplicate and the results are expressed as mean zones of inhibition $(\mathrm{mm}) \pm \mathrm{SEM}$. 
The $P$. colorata leaf hydro-alcohol extract also inhibited S. pyogenes growth (Figure 7 zone of inhibition $=7.8 \pm 0.4 \mathrm{~mm}$ ). This is a significant result as the ampicillin control only inhibited $S$. pyogenes growth with low efficacy $(6.6 \pm 0.3 \mathrm{~mm})$, indicating that the $S$. pyogenes strain tested in our study was ampicillin resistant. This supports previous studies which have also reported low susceptibility of this $S$. pyogenes strains to several conventional antibiotics. ${ }^{10-12}$ In contrast, $S$. pyogenes was highly susceptible to chloramphenicol, with an inhibition zone of $10.2 \pm 0.4$ $\mathrm{mm}$ )

The antimicrobial efficacy was further quantified by determining the MIC values for each extract against the microbial species which were determined to be susceptible. The P. colorata leaf hydro-alcohol extract was a potent growth inhibitor of several bacterial species/strains (as judged by MIC; Table 3). A. baylyi was the most susceptible bacteria to the $P$. colorata leaf hydro-alcohol extract, with MIC values as low as $427 \mu \mathrm{g} / \mathrm{mL}$ (approximately $4 \mu \mathrm{g}$ infused into the disc) recorded against this bacteria. The extract was also a moderate inhibitor of both $P$. aeruginosa strains, with MIC's $<2500 \mu \mathrm{g} / \mathrm{mL}$. As both A. baylyi and P. aeruginosa are bacterial triggers of multiple sclerosis in genetically susceptible people, the $P$. colorata leaf hydro-alcohol extract has potential in the prevention and treatment of multiple sclerosis

The MIC values determined for the $P$. colorata leaf hydro-alcohol extract against the reference and clinical $P$. mirabilis strains also indicate potent growth inhibition (933 and $784 \mu \mathrm{g} / \mathrm{mL}$ respectively). The extract was a similarly potent inhibitor of $P$. vulgaris growth, with an MIC of $805 \mu \mathrm{g} /$ $\mathrm{mL}$. Proteus spp. infections (particularly P. mirabilis infections) are common causes of urinary tract infections and have also been identified as triggers of rheumatoid arthritis. ${ }^{16,17}$ Therefore, the $P$. colorata leaf hydroalcohol extract has potential for the prevention and treatment of these diseases in genetically susceptible individuals. In contrast, MICs $>1000$ $\mu \mathrm{g} / \mathrm{mL}$ were determined for all other bacterial strains, indicating only moderate growth inhibition for these bacteria.

\section{Quantification of toxicity}

The toxicity of the $P$. colorata leaf hydro-alcohol extract was initially tested in the Artemia franciscana nauplii bioassay at a concentration of $2000 \mu \mathrm{g} / \mathrm{mL}$ (Figure 8). For comparison, the reference toxin potassium

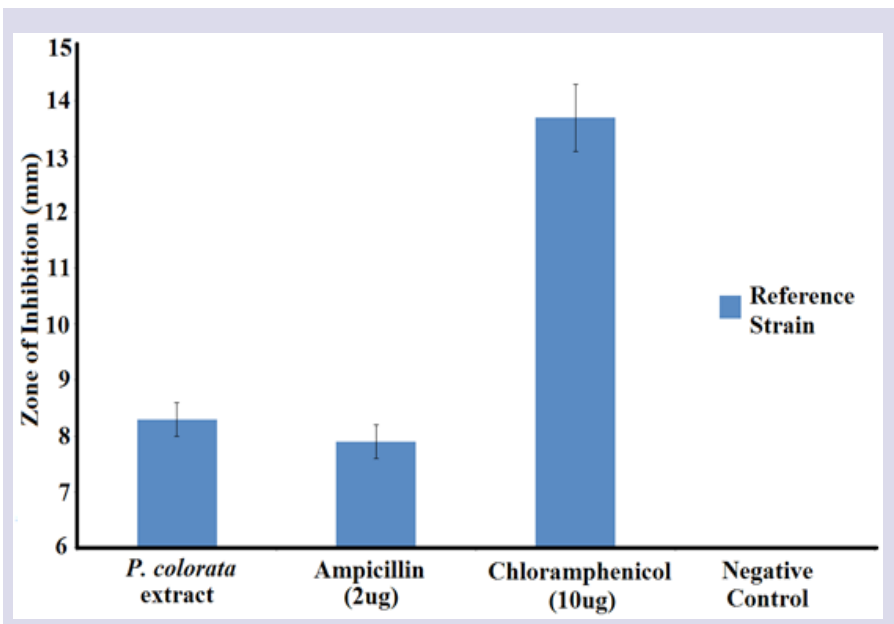

Figure 3: Growth inhibitory activity of $P$. colorata leaf hydro-alcohol extract and the ampicillin $(2 \mu \mathrm{g})$ and chloramphenicol $(10 \mu \mathrm{g})$ controls against $P$. vulgaris (ATCC:21719) measured as zones of inhibition ( $\mathrm{mm}$ ). All determinations were in at least triplicate and the results are expressed as mean zones of inhibition $(\mathrm{mm}) \pm$ SEM. dichromate $(1000 \mu \mathrm{g} / \mathrm{mL})$ was also tested in the bioassay. The potassium dichromate reference toxin was rapid in its onset of mortality, inducing nauplii death within the first 3 hours of exposure and $100 \%$ mortality was evident following 4-5 hours (results not shown). Whilst the extract also induced $100 \%$ mortality, a greater period of exposure was required to achieve $100 \%$ mortality. Indeed, less than $10 \%$ mortality was noted following 12 hours exposure and 24 hours was required to kill all of the nauplii (unpublished results). The $P$. colorata leaf hydro-alcohol extract therefore was deemed to be toxic (based on the screening study mortality) and the toxicity was further evaluated to determine the $\mathrm{LC}_{50}$.

To further quantify the effect of toxin concentration on the induction of mortality, the extract was serially diluted in artificial seawater to test across a range of concentrations in the Artemia nauplii bioassay (Table 3). For comparison, serial dilutions of potassium dichromate were also tested. The extract was determined to be nontoxic, with $\mathrm{LC}_{50}$ values substantially greater than $1000 \mu \mathrm{g} / \mathrm{mL}$ following $24 \mathrm{~h}$ exposure. Extracts with an $\mathrm{LC}_{50}$ of greater than $1000 \mu \mathrm{g} / \mathrm{mL}$ towards Artemia nauplii have previously been defined as being nontoxic. ${ }^{34}$

\section{DISCUSSION}

Plant remedies are becoming increasingly sought after in the treatment of a myriad of diseases and disorders due both to their perception of greater safety than synthetic drugs and the failure of current drug regimens to effectively treat many diseases. This is especially true for the autoimmune inflammatory diseases. The current treatments utilising disease modifying anti-rheumatic drugs (DMARDs) to alleviate the symptoms of these diseases and/or alter the disease progression are not entirely effective and have been associated with numerous adverse effects. ${ }^{15}$ Furthermore, many of the current treatments aimed to treat the symptoms without addressing the underlying causes and pathogenic mechanisms. Therefore, whilst these treatments may alleviate pain, redness, swelling etc., they do not address the tissue degeneration which occurs as a consequence of the disease progression. A better understanding of the mechanisms for initiation and progression of the autoimmune inflammatory diseases is important for developing new drugs to target specific processes and thus more effectively treat autoimmune inflammatory diseases.

Our study examined the ability of a commercial P. colorata leaf hydro-

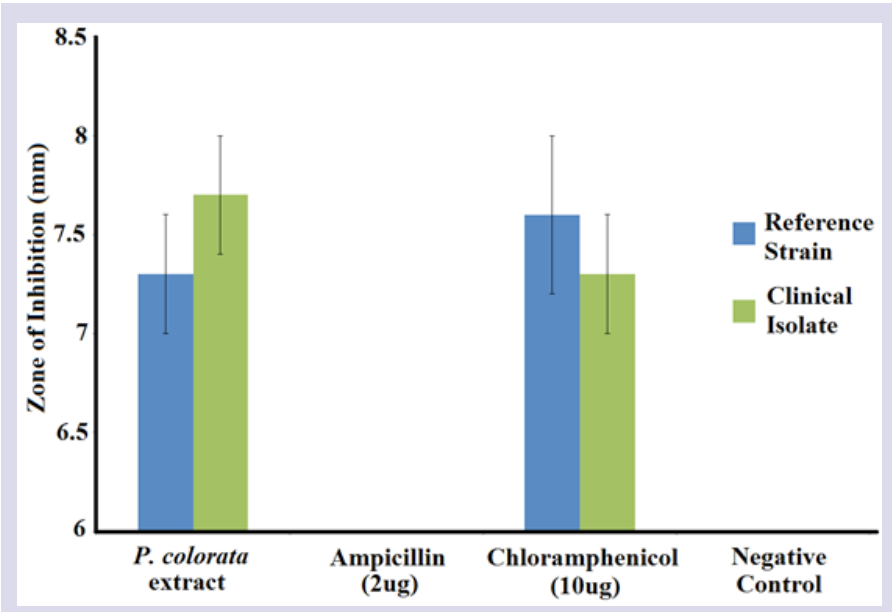

Figure 4: Growth inhibitory activity of $P$. colorata leaf hydro-alcohol extract and the ampicillin $(2 \mu \mathrm{g})$ and chloramphenicol $(10 \mu \mathrm{g})$ controls against $K$. pneumoniae measured as zones of inhibition $(\mathrm{mm})$. The blue bars represent the inhibitory activity against the reference strain (ATCC:31488) and the green bars represent the zones of inhibition against the clinical strain. All determinations were in at least triplicate and the results are expressed as mean zones of inhibition $(\mathrm{mm}) \pm \mathrm{SEM}$. 


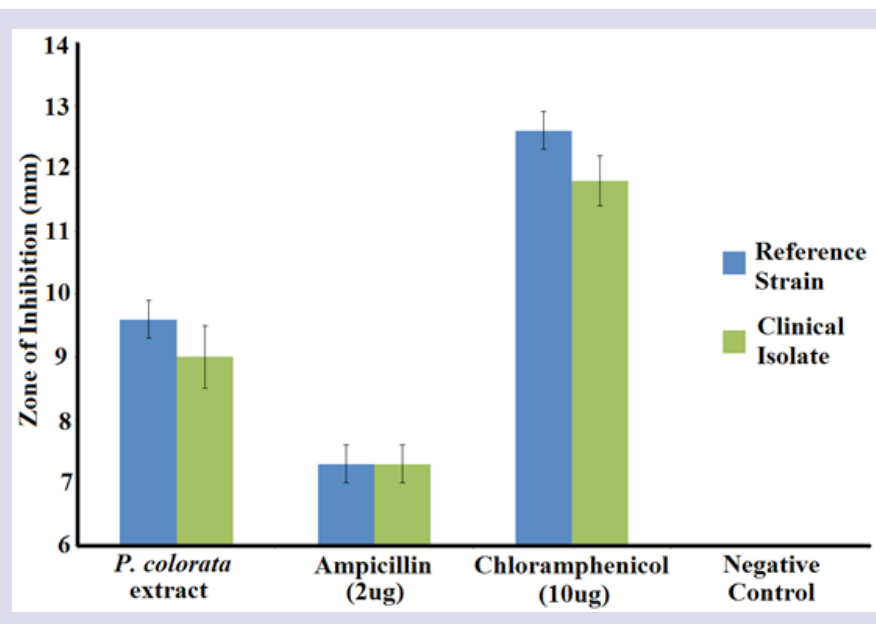

Figure 5: Growth inhibitory activity of $P$. colorata leaf hydro-alcohol extract and the ampicillin $(2 \mu \mathrm{g})$ and chloramphenicol $(10 \mu \mathrm{g})$ controls against $A$. baylyi measured as zones of inhibition ( $\mathrm{mm}$ ). The blue bars represent the inhibitory activity against the reference strain (ATCC:33304) and the green bars represent the zones of inhibition against the clinical strain. All determinations were in at least triplicate and the results are expressed as mean zones of inhibition $(\mathrm{mm}) \pm$ SEM.

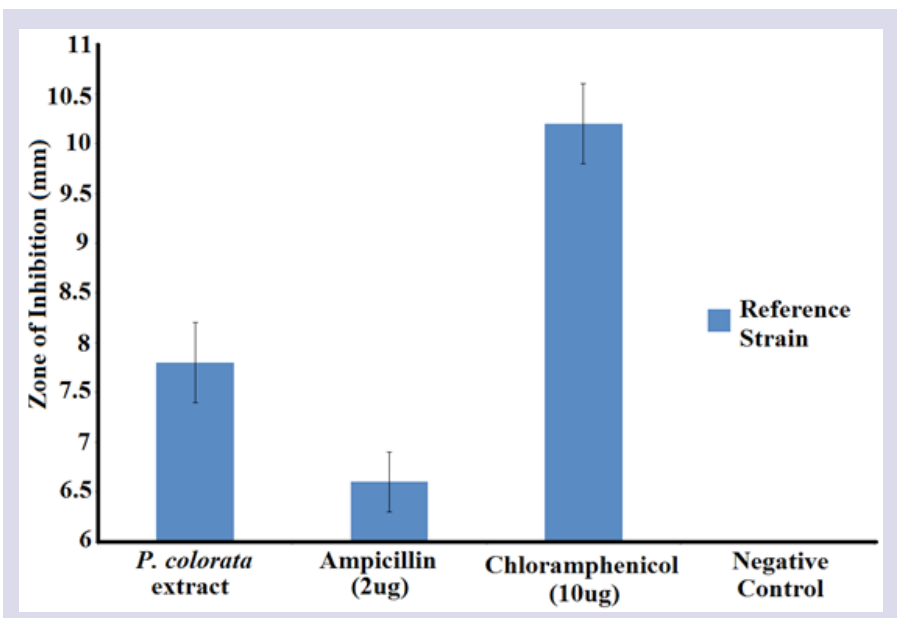

Figure 7: Growth inhibitory activity of $P$. colorata leaf hydro-alcohol extract and the ampicillin $(2 \mu \mathrm{g})$ and chloramphenicol $(10 \mu \mathrm{g})$ controls against $S$. pyogenes (clinical isolate) measured as zones of inhibition $(\mathrm{mm})$. All determinations were in at least triplicate and the results are expressed as mean zones of inhibition $(\mathrm{mm}) \pm \mathrm{SEM}$.

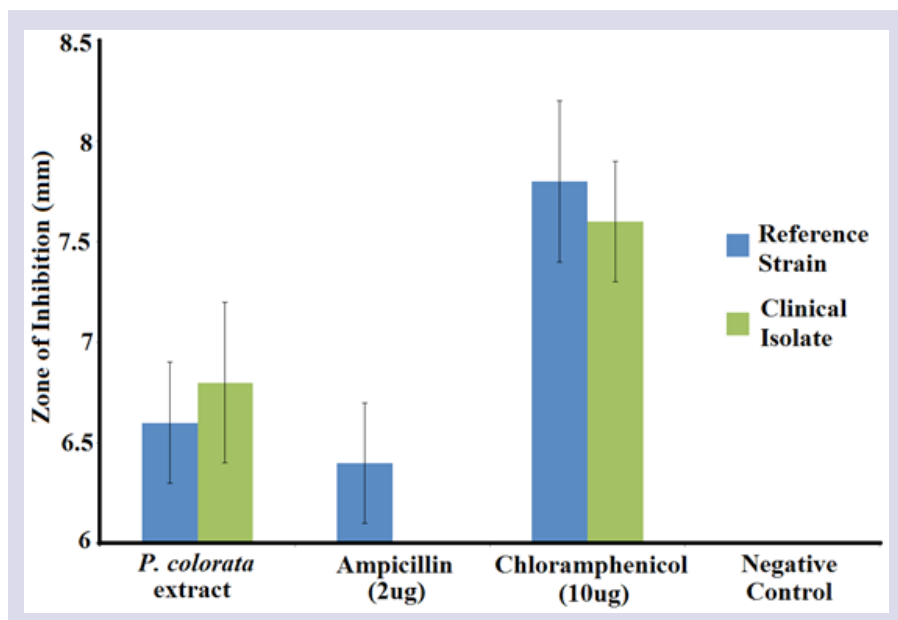

Figure 6: Growth inhibitory activity of $P$. colorata leaf hydro-alcohol extract and the ampicillin $(2 \mu \mathrm{g})$ and chloramphenicol $(10 \mu \mathrm{g})$ controls against $P$. aeruginosa measured as zones of inhibition $(\mathrm{mm})$. The blue bars represent the inhibitory activity against the reference strain (ATCC:39324) and the green bars represent the zones of inhibition against the clinical strain. All determinations were in at least triplicate and the results are expressed as mean zones of inhibition $(\mathrm{mm}) \pm \mathrm{SEM}$.

Table 3: Minimum bacterial growth inhibitory concentration $(\mu \mathrm{g} / \mathrm{mL})$ of the P. colorata hydro-alcohol and LC50 values $(\mu \mathrm{g} / \mathrm{mL})$ in the Artemia nauplii bioassay.

\begin{tabular}{|c|c|c|c|c|}
\hline \multirow{2}{*}{$\begin{array}{l}\text { Bacterial } \\
\text { Species }\end{array}$} & \multirow[t]{2}{*}{ Strain } & \multirow{2}{*}{$\begin{array}{c}\text { MIC }(\mu \mathrm{g} / \\
\mathrm{mL})\end{array}$} & \multicolumn{2}{|c|}{$\mathrm{LC}_{50}(\mu \mathrm{g} / \mathrm{mL})$} \\
\hline & & & $24 \mathrm{~h}$ & $48 \mathrm{~h}$ \\
\hline \multirow[t]{2}{*}{ P. mirabilis } & ATCC:21721 & 933 & NT & NT \\
\hline & Clinical isolate & 784 & NT & NT \\
\hline P. vulgaris & ATCC:21719 & 805 & NT & NT \\
\hline \multirow[t]{2}{*}{ K. pneumoniae } & ATCC:213488 & 1570 & NT & NT \\
\hline & Clinical isolate & 1358 & NT & NT \\
\hline \multirow[t]{2}{*}{ A. baylyi } & ATCC:33304 & 635 & NT & NT \\
\hline & Clinical isolate & 427 & NT & NT \\
\hline \multirow[t]{2}{*}{ P. aeruginosa } & ATCC:39324 & 2366 & NT & NT \\
\hline & Clinical isolate & 2180 & NT & NT \\
\hline S. pyogenes & Clinical isolate & 1446 & NT & NT \\
\hline A. franciscana & nauplii & NT & 1365 & 1147 \\
\hline \multicolumn{5}{|c|}{$\mathrm{NT}=$ not tested } \\
\hline
\end{tabular}

alcohol extract to inhibit the growth of some bacterial triggers of autoimmune inflammatory diseases. The extract was a particularly potent inhibitor of P. mirabilis, P. vulgaris and A. baylyi, with MIC values substantially $<1000 \mu \mathrm{g} / \mathrm{mL}$. As $P$. mirabilis (and possibly P. vulgaris) can trigger rheumatoid arthritis in genetically susceptible individuals. ${ }^{16,17}$ these extracts have potential for the development of rheumatoid arthritis inhibitory therapies. Similarly, as A. baylyi is a trigger of multiple sclerosis, the $P$. colorata leaf hydro-alcohol extract also has potential in prevention and treatment of this disease. P. aeruginosa may also trigger multiple sclerosis in some people. Interestingly, the extract was also inhibited the growth of this bacterium (albeit with substantially lower potency), further attesting to its therapeutic properties in people genetically sus- ceptible to multiple sclerosis. Furthermore, the extract also displayed moderate K. pneumoniae and S. pyogenes growth inhibitory properties, As K. pneumoniae and S. pyogenes can trigger ankylosing spondylitis and rheumatic fever respectively in genetically susceptible individuals, ${ }^{16}$ the $P$. colorata leaf hydro-alcohol extract may also be useful in the prevention and treatment of these diseases.

Whilst a detailed investigation of the phytochemistry of the P. colorata leaf hydro-alcohol extract was beyond the scope of our study, qualitative screening studies were used to determine the classes of compounds present. The extract contained relatively high levels of total phenolics, flavonoids and saponins. Lower levels of tannins and triterpenoids were also detected. It is likely that these and other phytochemical classes may 


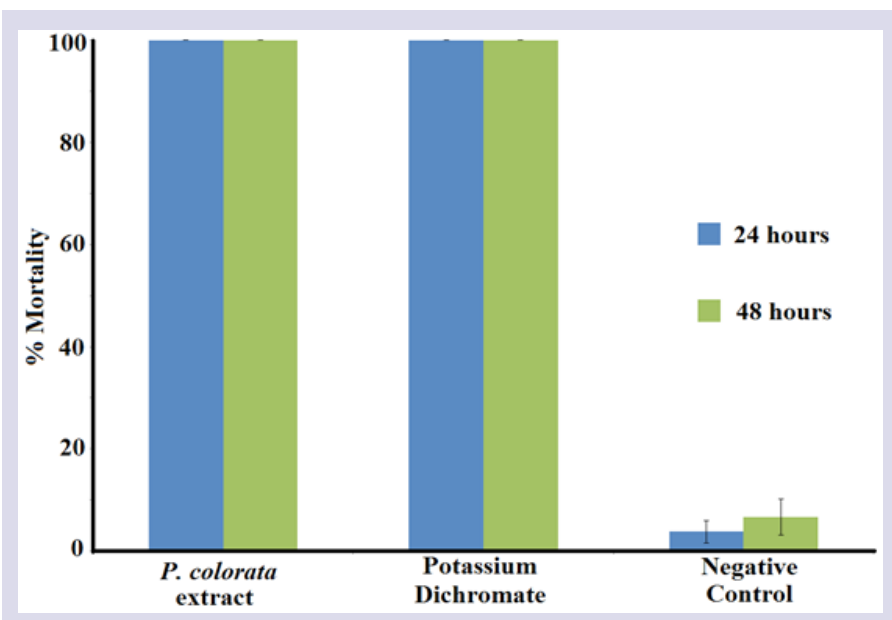

Figure 8: The lethality of $P$. colorata leaf hydro-alcohol extract $(2000 \mu \mathrm{g} /$ $\mathrm{mL})$, potassium dichromate $(1000 \mu \mathrm{g} / \mathrm{mL})$ and a seawater control. Blue bars represent the \% mortality following $24 \mathrm{~h}$ exposure to the extract/ toxin. Green bars represent the \% mortality following $48 \mathrm{~h}$ exposure to the extract/toxin. All bioassays were performed in at least triplicate and are expressed as mean \pm SEM.

contribute to the growth inhibitory properties of these extracts. Many studies have reported potent antibacterial activities for a wide variety of these compounds. ${ }^{6}$ Further phytochemical evaluation studies and bioactivity driven isolation of active components is required to evaluate the mechanism of bacterial growth inhibition.

The findings reported here also demonstrate that the $P$. colorata leaf hydro-alcohol extract was nontoxic towards Artemia franciscana nauplii, with $24 \mathrm{~h}$ and $48 \mathrm{~h} \mathrm{LC}_{50}$ values of 1365 and $1147 \mu \mathrm{g} / \mathrm{mL}$ respectively. Extracts with $\mathrm{LC}_{50}$ values $>1000 \mu \mathrm{g} / \mathrm{mL}$ towards Artemia nauplii are defined as being nontoxic. ${ }^{34}$ Whilst our preliminary toxicity studies indicate that the $P$. colorata leaf extract may be safe for therapeutic use, studies using human cell lines are required to further evaluate the safety of these extracts. Furthermore, whilst these studies have demonstrated the potential of the P. colorata leaf hydro-alcohol extract in the development of future antibiotic chemotherapeutics for the prevention and treatment of autoimmune diseases, more work is required to isolate the inhibitory components and to determine the mechanism of inhibition.

\section{CONCLUSION}

The results of this study demonstrate the potential of the P. colorata leaf hydro-alcohol extract for the prevention and treatment of rheumatoid arthritis, ankylosing spondylitis, multiple sclerosis and rheumatic fever in genetically susceptible people. Furthermore, the lack of toxicity indicates than the extract is safe for therapeutic use. Further studies aimed at the purification and identification of bioactive components are required to examine the mechanisms of action of these agents.

\section{ACKNOWLEDGEMENT}

The authors are grateful to Michelle Mendell and Jane Gifkins for the gift of the clinical isolate bacterial strains used in this study. Financial support for this work was provided by the Environmental Futures Research Institute and the School of Natural Sciences, Griffith University, Australia.

\section{CONFLICTS OF INTEREST}

The authors report no conflicts of interest.

\section{ABBREVIATIONS}

DMSO: Dimethyl sulfoxide; $\mathrm{LC}_{50}$ : The concentration required to achieve $50 \%$ mortality; MIC: minimum inhibitory concentration

\section{REFERENCES}

1. Marquínez X, Lohmann LG, Faria Salatino ML, et al. Generic relationships and dating of lineages in Winteraceae based on nuvclear (ITS) and plastid (rpS16 and psbA-trnH) sequence data. Mol Phylogenet Evol. 2009;53(2):435-49.

2. Vink W. Taxonomy of Winteraceae. Taxon 1988;37:691-8.

3. Mabberley DJ. Mabberley's plant-book: a portable dictionary of plants, their classifications and uses. Cambridge University Press. 2008.

4. Field TS, Zwieniecki MA, Holbrook NM. Winteraceae evolution: An Eco physiological perspective. Ann Missouri Bot Gard. 2000;87(3):323-34.

5. Correa MP. Diccion'ario das plantas 'uteis do Brasil e das ex'oticas cultivadas. Rio de Janeiro: Imprensa Nacional 1984;2.

6. Cock IE. The phytochemistry and chemotherapeutic potential of Tasmannia lanceolata (Tasmanian pepper): A review. Pharmacog Commn. 2013;3(4):13-5. DOI: $10.5530 /$ pc. 2013.4 .3

7. Riley M. Maori healing and herbal: New Zealand ethnobotanical sourcebook. 1994, Paraparaumu, New Zealand: Viking Sevenseas: 199

8. Halliwell B, Gutteridge MCJ. Free radicals in biology and medicine. $3^{\text {rd }}$ ed., $O X$ ford University Press, Oxford;1999.

9. Gey KF. Cardiovascular disease and vitamins: concurrent correction of 'suboptimal' plasma antioxidant levels may, as an important part of the 'optimal' nutrition, help to prevent early stages of cardiovascular disease and cancer, respectively. Bibliotheca Nutritio et Dieta 1995;52:75-91.

10. Courtney R, Sirdaarta J, Matthews B, et al. Tannin components and inhibitory activity of Kakadu plum leaf extracts against microbial triggers of autoimmune inflammatory diseases. Pharmacog J. 2015;7(1):18-31. DOI: 10.5530/pj.2015.7.2

11. Sirdaarta J, Matthews B, White A, et al. GC-MS and LC-MS analysis of Kakadu plum fruit extracts displaying inhibitory activity against microbial triggers of multiple sclerosis. Pharmacog Commn. 2015;5(2):100-15. DOI: 10.5530/pc.2015.2.2

12. Sirdaarta, J, Matthews B, Cock IE. Kakadu plum fruit extracts inhibit growth of the bacterial triggers of rheumatoid arthritis: Identification of stilbene and tannin components. J Functional Foods. 2015;17:610-20. DOI: 10.1016/j.jff.2015.06.019

13. Sautron C, Cock IE. Antimicrobial activity and toxicity of Syzygium australe and Syzygium leuhmannii fruit extracts. Pharmacognosy Communications 2014;4(1):53-60. DOI: 10.5530/pc.2014.1.8

14. Winnett $\mathrm{V}$, Boyer $\mathrm{H}$, Sirdaarta J, et al. The potential of Tasmannia lanceolata as a natural preservative and medicinal agent: Antimicrobial activity and toxicity. Pharmacog Commn. 2014;4(1):42-52.DOI: 10.5530/pc.2014.1.7

15. Alataha D, Kapral T, Smolen JS. Toxicity profiles of traditional disease modifying antirheumatic drugs for rheumatoid arthritis. Ann Rheum Dis. 2003;62(5):482-6.

16. Ebringer A, Rashid T. Rheumatoid arthritis is an autoimmune disease triggered by Proteus urinary tract infection. Clin Develop Immunol. 2006;13(1):41-8.

17. Ebringer A, Cunningham $P$, Ahmadi $K$, et al. Sequence similarity between HLADR1 and DR4 subtypes associated with rheumatoid arthritis and Proteus/Serratia membrane haemolysins. Ann Rheum Dis. 1992;51(11):1245-46.

18. Hughes LE, Smith PA, Natt RS, et al. Cross-reactivity between related sequences found in Acinetobacter sp., Pseudomonas aeruginosa, myelin basic protein and myelin oligodendrocyte glycoprotein in multiple scherosis. J Neuroimmunol. 2003;144(1):105-15

19. Beermann C, Wunderli-Allenspach H, Groscurth $P$, et al. Lipoproteins from Borrelia burgdorferi applied in liposomes and presented to dendritic cells induce CD8+ T-lymphocytes in vitro. Cell Immunol. 2000;201(2):124-31.

20. Kollef MH, West S, Davis DR, et al. Central and peripheral nervous system demyelination after infection with Mycoplasma pneumoniae. Evidence of an autoimmune process. Southern Med J. 1991;84(10):1255-8.

21. Cock I, van Vuuren SF. Anti-Proteus activity of some South African medicinal plants: their potential for the prevention of rheumatoid arthritis. Inflammopharmacology. 2014;22(1):23-36. DOI:10.1007/ s10787-013-0179-3

22. Nepom GT, Byers P, Seyfried C, Healey LA, Wilske KR, Stage D, Nepom BS. HLA genes associated with rheumatoid arthritis. Arthritis Rheum 1989;32(1):15-21.

23. Vesoul J, Cock IE. An examination of the medicinal potential of Pittosporum phylloraeoides: Toxicity, antibacterial and antifungal activities. Pharmacog Commn. 2011;1(2):8-17.

24. Boyer $\mathrm{H}$, Cock IE. Evaluation of the potential of Macademia integriflora extracts as antibacterial food agents. Pharmacog Commn. 2013;3(3):53-62

25. Winnett $V$, Sirdaarta J, White A, et al. Inhibition of Klebsiella pneumoniae growth by selected Australian plants: natural approaches for the prevention and management of ankylosing spondylitis. Inflammopharmacol. 2017;25(2):22335. DOI: $10.1007 / \mathrm{s} 10787-017-0328-1$

26. Arkhipov A, Sirdaarta J, Rayan P, et al. An examination of the antibacterial, antifungal, anti-Giardial and anticancer properties of Kigelia africana fruit extracts. Pharmacog Commn. 2014;4(3):62-76. 
27. Cock I, Mohanty S, White A, et al. Colloidal silver (CS) as an antiseptic: Two opposing viewpoints. Pharmacog Commn. 2012;2(1):49-58.

28. Mohanty S, Cock IE. Bioactivity of Syzygium jambos methanolic extracts: Antibacterial activity and toxicity. Pharmacog Res. 2010;2(1):4-9.

29. Kalt FR, Cock IE. GC-MS analysis of bioactive Petalostigma extracts: Toxicity, antibacterial and antiviral activities. Pharmacog Mag. 2014;10 (37 Suppl):S37S48.

30. Cock IE, Winnett V, Sirdaarta J, et al. The potential of selected Australian medicinal plants with anti-Proteus activity for the treatment and prevention of rheumatoid arthritis. Pharmacog Mag. 2015;11(42):S190-S208.

31. Cock IE, Kukkonen L. An examination of the medicinal potential of Scaevola spinescens: Toxicity, antibacterial and antiviral activities. Pharmacog Res. $2011 ; 3(2): 85-94$

32. Vesoul J, Cock IE. The potential of Bunya nut extracts as antibacterial functional food agents. Pharmacog Commn. 2012;2(1):72-9.

33. Sirdaarta J, Cock IE. Vitamin E and Trolox ${ }^{\mathrm{TM}}$ reduce toxicity of Aloe barbadensis Miller juice in Artemia franciscana nauplii but individually are toxic at high concentrations. Int J Toxicol. 2008; 5, 1.

34. Ruebhart DR, Wickramasinghe W, Cock IE. Protective efficacy of the antioxidants vitamin $\mathrm{E}$ and Trolox against Microcystis aeruginosa and microcystin-LR in Artemia franciscana nauplii. J Toxicol Environ Health Part A. 2009;72(24):156775.

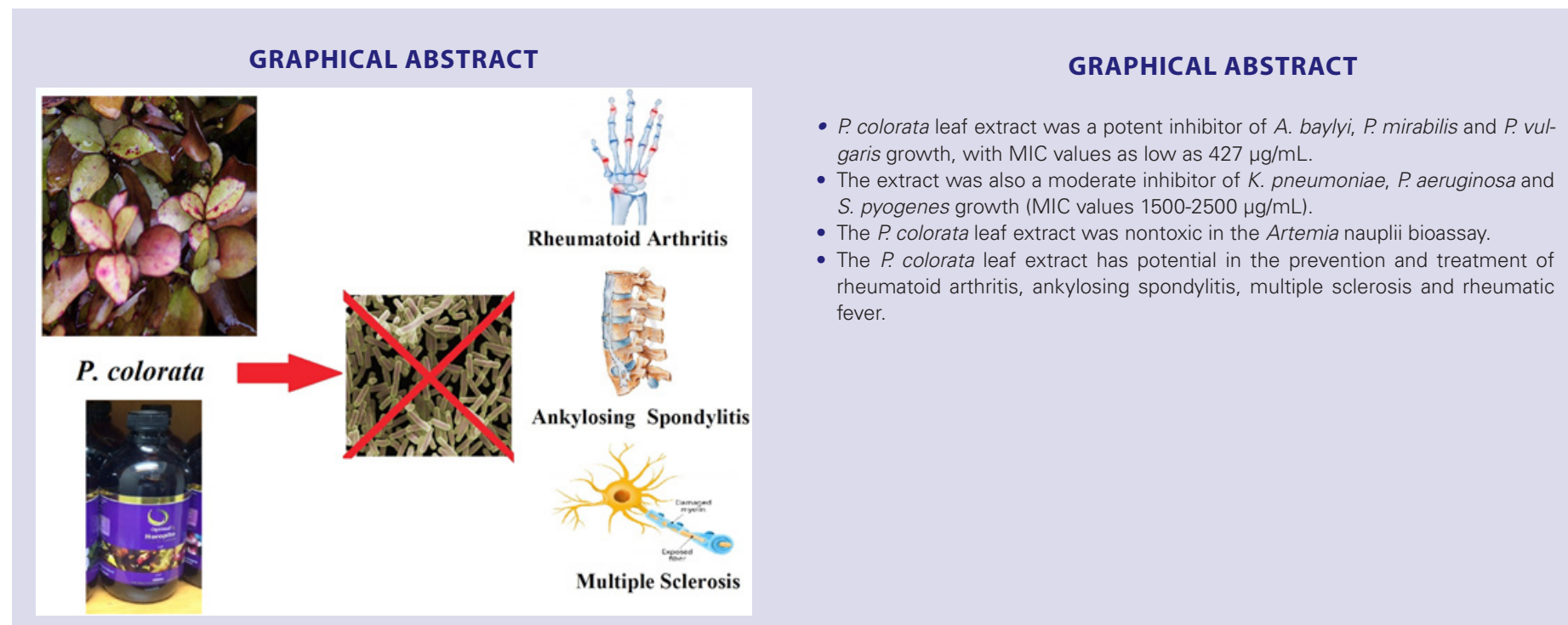

ABOUT AUTHORS

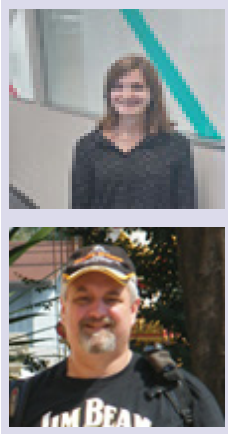

Ms Celia Barillot: is a postgraduate student at School of Biology, Ecole de Biologie Industrielle (EBI), Cergy, France. In 2016, she undertook a research project in Dr lan Cock's laboratory in the School of Natural Sciences at Griffith University examining the therapeutic properties of a variety of traditional medicine plants.

Dr lan Cock: leads a research team in the Environmental Futures Research Institute and the School of Natural Sciences at Griffith University, Australia. His research involves bioactivity and phytochemical studies into a variety of plant species of both Australian and international origin, including Aloe vera, South Asian and South American tropical fruits, as well as Australia plants including Scaevola spinescens, Pittosporum phylliraeoides, Terminalia ferdinandiana (Kakadu plum), Australian Acacias, Syzygiums, Petalostigmas and Xanthorrhoea johnsonii (grass trees). This range of projects has resulted in nearly 200 publications in a variety of peer reviewed journals. 